\title{
Mechanical Properties of Waste Glass Aggregates Concrete Improved with Integral Waterproofing Admixture
}

\author{
Ayam Jabbar Jihad, Afrah Abdulwahhab Jaber, Rusul Ali Aldahir and \\ Llayth Abdulrasool Mahdi Alasadi \\ Faculty of Engineering, The University of Kufa, Najaf, Iraq
}

\begin{abstract}
The use of waste aggregate in concrete is very important because of that decrease the total cost of concrete and lead to a more clean environment. This research aims to study the mechanical properties such as compressive, tensile and flexural strength and also the modulus of elasticity for concrete containing waste glass as coarse and fine aggregate and improved also with integral waterproofing admixture. The study shows the improvement in mechanical properties due to using waste glass only and waste glass with integral waterproofing admixture, compressive strength increased from 27.3-35.8 MPa by total glass replacement but using both glass and waterproof lead to rise compressive strength to $54.38 \mathrm{MPa}$ also other mechanical properties increased highly by using glass and waterproofing admixture .
\end{abstract}

Key words: Waste aggregate, integral waterproofing, compressive strength, flexural strength, modulus of elasticity, waterproof

\section{INTRODUCTION}

Waste materials such as waste plastics, glass, iron chips, etc. can be used as aggregate in concrete to decrease cost and also lead to the more clean environment, the use of waste glass as aggregate in concrete was first reported [over about 60 years ago (Liang et al., 2007). Some investigations show that the use of waste plastics as replacement of coarse aggregate increase compressive, tensile and flexural strength until $20 \%$ replacement then after this ratio the strength decreases (Subramani and Pugal, 2015). Waste concrete or destroyed concrete can also be used as coarse aggregate in concrete and can improve the mechanical properties (Chandra et al., 2017) this research aim to improve the mechanical properties of concrete by using waste glass as a coarse and fine aggregate with using integral waterproof admixture.

\section{MATERIALS AND METHODS}

Experimental program: Using ordinary Portland cement type (I) in all mixes, the mix proportions ingredients shown in Table 1 that contain normal sand and gravel. The grading of fine and coarse aggregates are shown in Table 2 and 3 and it confirms with British standards 882 (BSI., 1992), the replacement of coarse and fine aggregate were done by using weight replacement of 25 , 50,75 and $100 \%$ replacements and with same mix
Table 1: Mix proportions for reference mix

\begin{tabular}{|c|c|c|c|c|}
\hline Ingredient & Cement & Fine aggregate & Coarse aggregate & Water \\
\hline $\begin{array}{l}\text { Weight for } 1 \text { cubic } \\
\text { meter concrete }\end{array}$ & 340 & 720 & 1200 & 150 \\
\hline \multicolumn{5}{|c|}{ Table 2: Grading of fine glass waste aggregate used in the study. } \\
\hline Sieve size & \multicolumn{2}{|c|}{ Passing $(\%)$} & \multicolumn{2}{|c|}{$\begin{array}{l}\text { Passing by weight (BS } \\
\text {-specification-882) }(\%)\end{array}$} \\
\hline $10 \mathrm{~mm}$ & \multicolumn{2}{|c|}{100} & \multicolumn{2}{|l|}{100} \\
\hline $5 \mathrm{~mm}$ & \multicolumn{2}{|c|}{100} & \multicolumn{2}{|l|}{100} \\
\hline $2.36 \mathrm{~mm}$ & \multicolumn{2}{|c|}{96.2} & \multicolumn{2}{|l|}{$80-100$} \\
\hline $1.18 \mathrm{~mm}$ & \multicolumn{2}{|c|}{89.7} & \multicolumn{2}{|l|}{$70-100$} \\
\hline 600 micron & \multicolumn{2}{|c|}{79.4} & \multicolumn{2}{|l|}{$55-100$} \\
\hline 300 micron & \multicolumn{2}{|c|}{33.5} & \multicolumn{2}{|l|}{$5-70$} \\
\hline 150 micron & \multicolumn{2}{|c|}{ - } & \multicolumn{2}{|l|}{-} \\
\hline
\end{tabular}

Table 3: Grading of course waste aggregates used in the study for $10 \mathrm{~mm}$ max. size aggregate

\begin{tabular}{lcc}
\hline $\begin{array}{l}\text { Sieve } \\
\text { size }(\mathrm{mm})\end{array}$ & Passing by weight $(\%)$ & $\begin{array}{c}\text { Passing limits (B-S, } \\
\text { specification } 882,1992)(\%)\end{array}$ \\
\hline 20 & 100 & 100 \\
14 & 100 & 100 \\
10 & 86.3 & $85-100$ \\
5 & 11.8 & $0-25$ \\
2.36 & 0.9 & $0-5$ \\
\hline
\end{tabular}

proportions of reference mix. The waste glass was obtained by crushing waste glass bottles and cans, it crushed to fine and coarse waste aggregate as shown in Fig. 1, the waterproof admixture used in the study is from type integral waterproofing admixture and shown in Fig. 2. Table 4 shows some properties of integral waterproofing admixture. The integral waterproofing used as a percentage of cement weight and it used as $2 \%$ of cement weight.

Corresponding Author: Ayam Jabbar Jihad, Faculty of Engineering, The University of Kufa, Najaf, Iraq 
Table 4: Some properties of integral waterproofing admixture used in the study

\begin{tabular}{lllll}
\hline Waterproofing type & Color & Specific gravity & Type & Chemical composition \\
$\begin{array}{l}\text { Integral waterproof } \\
\text { ADM-10-1110 }\end{array}$ & Dark brown & $1.03-1.05$ at $20^{\circ} \mathrm{C}$ & Liquid & $\begin{array}{l}\text { Polycarboxylate liquid polymers and } \\
\text { other compounds like organic compounds }\end{array}$ \\
\hline
\end{tabular}

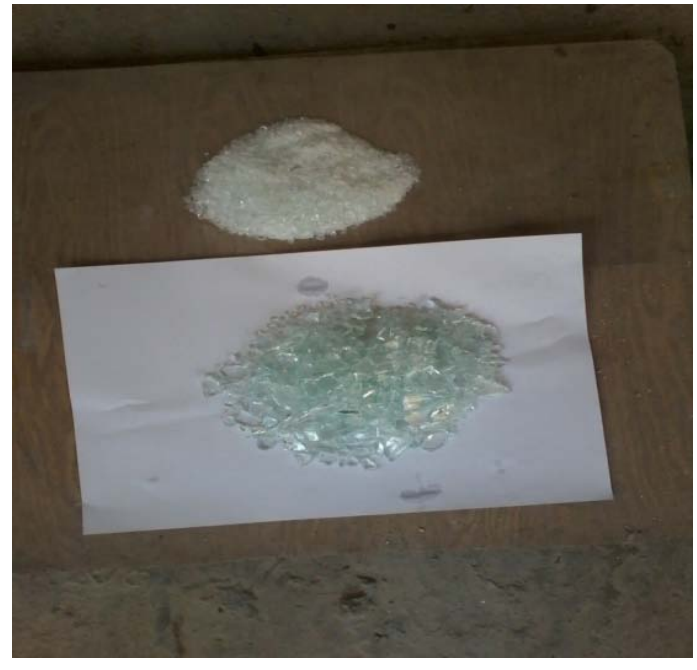

Fig. 1: Coarse and fine waste glass used in the study

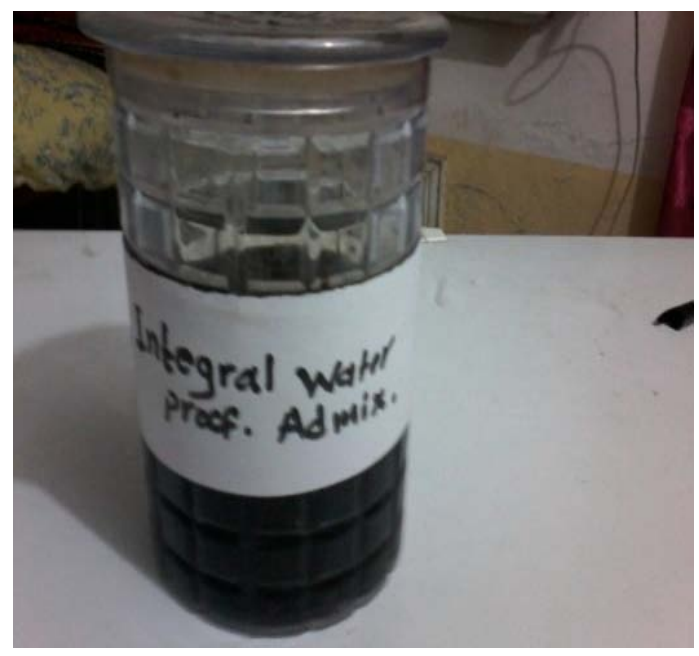

Fig. 2: Integral waterproofing admixture used in the study

Specimens and tests: Cubic molds specimens with $100 \times 100 \times 100 \mathrm{~mm}$ used for compressive tests and using 3 specimens for each test and finding the average in 28 days, the tensile test was done by using $100 \times 200$ cylinders and finding indirect tensile strength (splitting test), the flexural strength tests done by using $100 \times 100 \times 400 \mathrm{~mm}$ beams and loading specimens for third point loading testing according to B.S (1881) standards. Finally, the modulus of elasticity done by using $150 \times 300 \mathrm{~mm}$ cylinders with mechanical strain gauges to find strain values under gradual

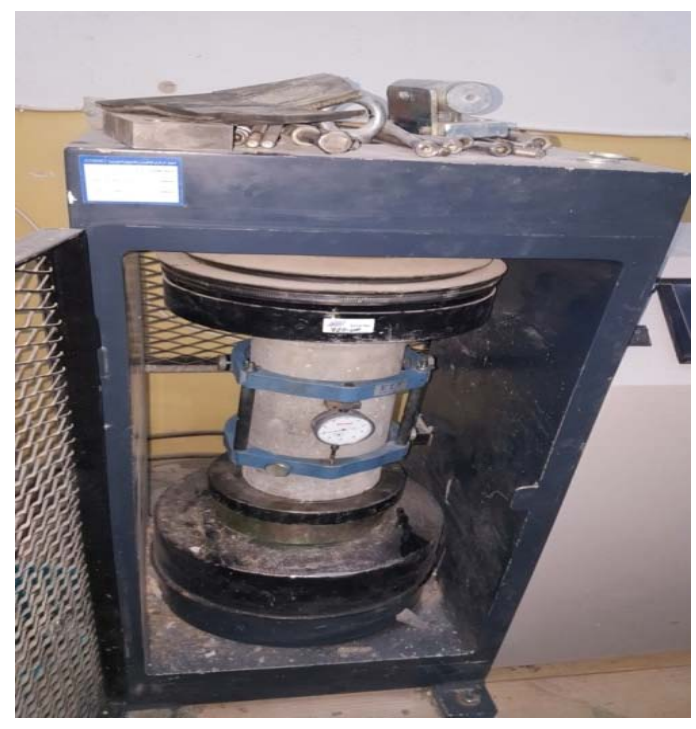

Fig. 3: Cylindrical concrete specimen under testing for stress-strain behavior

compressive load as shown in Fig. 3 from stress-strain values test, the modulus of elasticity can be obtained for each specimen.

\section{RESULTS AND DISCUSSION}

Table 5 shows the results of mechanical properties of reference mixes and waste glass concrete data and Table 6 show data of concrete with waste glass and contain integral waterproofing admixture also (Fig. 4-7) show the comparison of mechanical properties of concrete contains only waste glass aggregate and concrete with both waste glass a waterproofing admixture.

For waste glass concrete, the replacement of fine and coarse aggregate lead to increase values of compressive strength from 27.3-35.8 MPa (for 100\% replacement) and that can be attributed to the nature of glass that has excellent bond with cement mortar because of its sharp edges of particles and pieces, tensile strength also increased from 1.9-3.2 $\mathrm{MPa}$ and flexural strength increased from 2.3-4.96 $\mathrm{MPa}$ also the modulus of elasticity increased from 20791-26083 MPa.

For concrete containing waste glass and waterproof admixture, the improvement in mechanical properties was 
Table 5: Mechanical properties of concrete with the replacement of coarse and fine aggregate with waste glass aggregates and without adding integral waterproof

\begin{tabular}{lcccc}
\multicolumn{2}{c}{ admixture } & & & \\
\hline Mix type & Compressive strength & Tensile strength & Flexural strength & Modulus of elasticity \\
\hline Reference mix & 27.32 & 1.92 & 2.33 & 20791 \\
$25 \%$ rep & 29.45 & 2.23 & 2.76 & 22014 \\
$50 \%$ rep & 31.89 & 2.54 & 3.12 & 23890 \\
$75 \%$ rep & 34.90 & 2.90 & 4.20 & 25134 \\
$100 \%$ rep & 35.84 & 3.18 & 4.96 & 26083 \\
\hline
\end{tabular}

Table 6: Mechanical properties of concrete with the replacement of coarse and fine aggregate with waste glass aggregates and with adding integral waterproof admixture

\begin{tabular}{|c|c|c|c|c|}
\hline Mix type & Compressive strength (MPa) & Tensile strength (MPa) & Flexural strength (MPa) & Modulus of elasticity (MPa) \\
\hline $\begin{array}{l}\text { Reference mix with } \\
\text { a waterproof admixture }\end{array}$ & 32.37 & 2.20 & 2.94 & 21847 \\
\hline $25 \%$ replacement & 36.82 & 2.77 & 3.60 & 23655 \\
\hline $50 \%$ replacement & 43.46 & 3.15 & 4.84 & 27519 \\
\hline $75 \%$ replacement & 51.74 & 3.80 & 5.73 & 32850 \\
\hline $100 \%$ replacement & 54.38 & 4.41 & 7.67 & 35301 \\
\hline
\end{tabular}

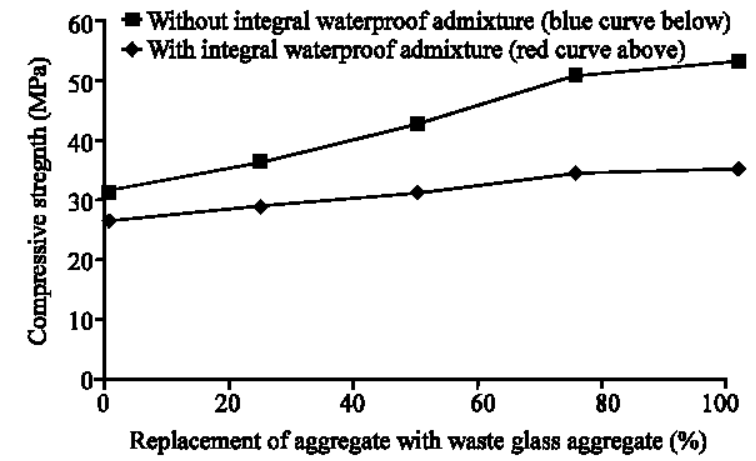

Fig. 4: Comparison between the compressive strength of waste glass aggregate concrete

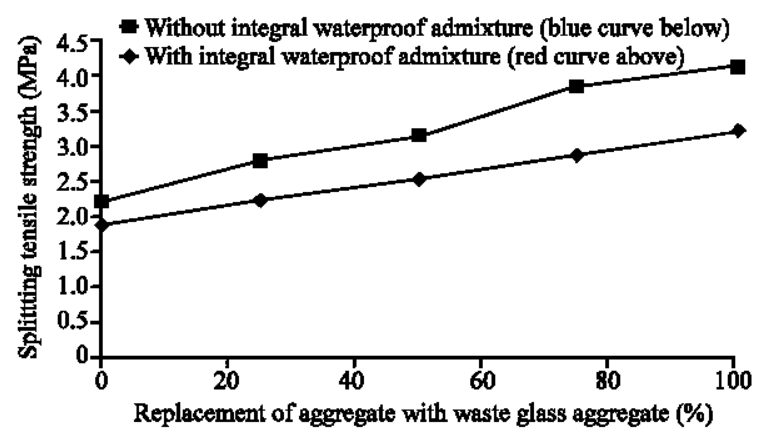

Fig. 5: Comparison between the tensile strength of waste glass aggregate concrete

higher, compressive strength here increased to $54.4 \mathrm{MPa}$, tensile strength increased to $4.41 \mathrm{MPa}$, flexural strength to $7.67 \mathrm{MPa}$ and modulus of elasticity increased to $35301 \mathrm{MPa}$ and these increments can be attributed to the action of integral waterproofing increased admixture the chemical particles of integral waterproof fill the

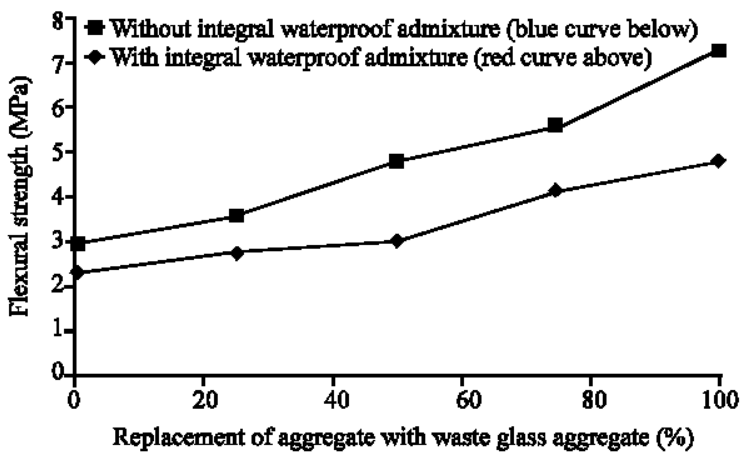

Fig. 6: Comparison between the flexural strength of waste glass aggregate concrete

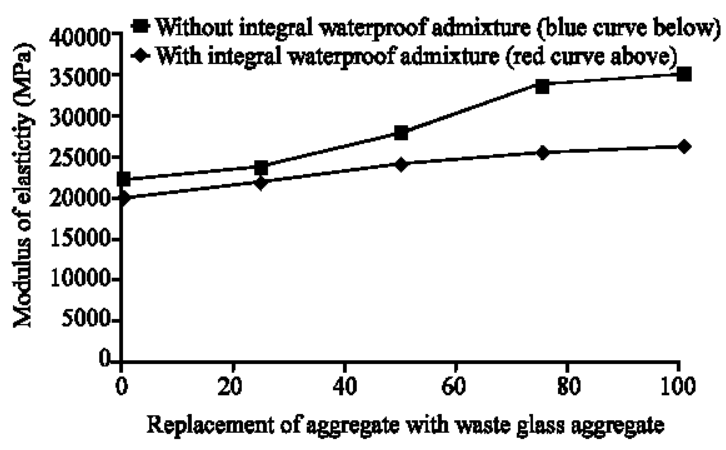

Fig. 7: Comparison between modulus of elasticity of waste glass aggregate concrete

microscopic pores in the concrete matrix as shown in Fig. 8 (Anonymous, 2010) and that give additional strength to concrete because of less pores inside it. Also, integral waterproofing concrete works as water reducer and that leads to fewer pores inside concrete and higher strength (Chan, 1999; Anonymous, 2017). 
(a)

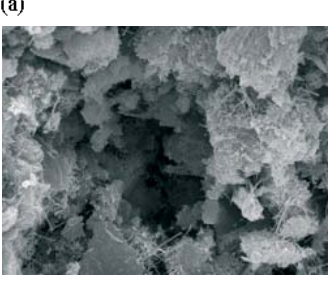

(b)

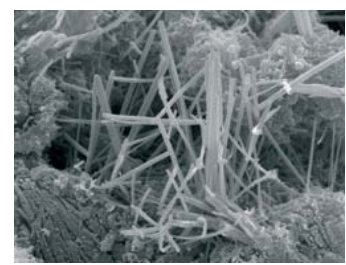

(c)

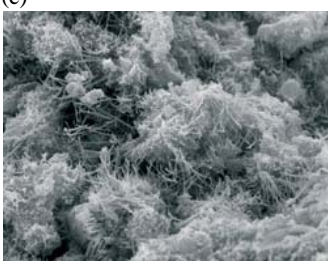

Fig. 8: (a-c) Microscope pictures show how crystalline of waterproof admixture can physically block the pores inside cement paste and voids completely sealed (BS, 1981).

\section{CONCLUSION}

Compressive, tensile and flexural strength increased with replacing normal aggregates with glass recycled aggregate and also modulus of elasticity because of higher bond with cement paste compressive strength increased from 27-35 $\mathrm{MPa}$ by using only replacement aggregates with waste glass but increased to about $54 \mathrm{MPa}$ with using integral waterproofing admixture. With using both glass aggregate and integral waterproofing admixture, the higher increment in compressive, tensile and flexural strength achieved and also higher values of modulus of elasticity and that attributed to fewer voids inside concrete and higher bonds of cement paste with aggregates.

\section{REFERENCES}

Anonymous, 2010. Understanding integral waterproofing. Inver Grove Heights, Minnesota. https://www. waterproofmag.com/downloads/2010-04/Understan ding_Integral_Waterproofing.pdf

Anonymous, 2017. Superplasticizers. Wikimedia Foundation, San Francisco, California, USA. https://en.wikipedia.org/wiki/Superplasticizer,

BS 1881: Part 118, 1983. Methods for Determination of Flexural Strength. British Standards Institution, London, ISBN: 0580129551.

BSI., 1992. Specification for aggregates from natural sources for concrete. British Standards Institution, London, UK.

Chan, R.W.M., 1999. Report on Concrete Admixtures for Waterproofing Construction. Structural Engineering Branch, Architectural Services Department, Queensway Government Offices, Hong Kong,

Chandra, A., S.H. Reddy and V. Gokulnath, 2017. Use of demolished waste in partial replacement of coarse aggregate in concrete. Intl. J. Adv. Res. Ideas Innovations Technol., 3: 171-176.

Liang, H., H. Zhu and E.A. Byars, 2007. Use of waste glass as aggregate in concrete. Proceedings of the 7th UK CARE Annual General Meeting, September 15, 2007, UK Chinese Association of Resources and Environment, Greenwich, London, UK., pp: 1-7.

Subramani, T. and V.K. Pugal, 2015. Experimental study on plastic waste as a coarse aggregate for structural concrete. Intl. J. Appl. Innovation Eng. Manage., 4: 144-152. 